\title{
MOVEMENT OF THE LESSER TROCHANTER IN
}

\section{PERTROCHANTERIC FRACTURE}

\author{
K. N. Norcross, M.A., F.R.C.S.
}

J. R. Pearson, F.R.C.S.

The Robert Jones and Agnes Hunt Orthopaedic Hospital, Oswestry.

INTERNAL fixation of pertrochanteric and intertrochanteric fractures of the femur has been regularly practised in this country for the past twenty years. In spite of this method of treatment, many patients are slow to recover the power of active hip flexion.

\section{Case Report}

A man of eighty-four sustained a pertrochanteric fracture of the right femur which was fixed with a Jowett blade plate. Four weeks after operation he suddenly complained of pain in the right knee for which no physical abnormality in the knee could be discovered; however, the ability to perform a straight leg raise was lost. A radiograph of the hip joint showed a shift of the lesser trochanter as compared with the radiognaph taken immediately after the operation (Figs. 1 and 2). A further month elapsed before he recovered the ability to raise the straight leg against gravity.

This report suggested that the integrity of the attachment of the ilio-psoas muscle determined the power of hip flexion. In fifteen patients who had sustained pertrochanteric and intertrochanteric fractures of the femur which had been fixed with a pin and plate, the power of hip flexion was measured at weekly intervals. The measurements were difficult to standardize because the patients were old, and their general improvement did not occur steadily. The diagram (Fig. 3) shows the method of measuring the power of hip flexion. Particular attention to the following details in order to standardize the procedure were made:

With the patient lying on her side the sling was placed at the correct position on the thigh -as distal as possible; the knee was flexed and the foot supported clear of the mattress; the resistance produced by the spring balance was such as to retain the hip in neutral flexionextension; the patient was encouraged to flex the hip without a jerking motion.

The measurements were recorded without detailed knowledge of the fracture being known to the observer, and the results were assessed separately.

\section{Results}

In eight patients the lesser trochanter was avulsed from the shaft, and in seven the lesser trochanter was not avulsed.

Two characteristic graphs are shown of the power of hip flexion (Figs. 4 and 5), showing the course of recovery with an intact lesser trochanter (Table 1) and with displacement of the lesser trochanter (Table 2). The force exerted on the spring balance is measured in pounds.

\section{TABLE 1}

POWER OF HIP FLEXION (POUNDS) MEASURED WEEKLY AFTER INTERNAL FIXATION OF PERTROCHANTERIC FRACTURE. LESSER TROCHANTER INTACT.

\section{(A.B., aged 45. Sound leg 50 lbs.)}

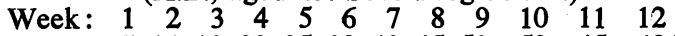

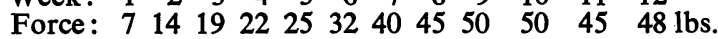

\section{TABLE 2}

POWER OF HIP FLEXION (POUNDS) MEASURED WEEKLY AFTER INTERNAL FIXATION OF PERTROCHANTERIC FRACTURE. LESSER TROCHANTER AVULSED.

\begin{tabular}{lllllllllllllll}
\multicolumn{1}{c}{ (F.G., aged 87. Sound leg 25 lbs.) } \\
Week: & 1 & 2 & 3 & 4 & 5 & 6 & 7 & 8 & 9 & 10 & 11 & 12 \\
Force: & 0 & 0 & 3 & 4 & 8 & 18 & 22 & 25 & 27 & 23 & 18 & 23 & lbs.
\end{tabular}

The characteristic features of the recovery of the power of hip flexion when the lesser trochanter is avulsed are the diminution of power in the first four or five weeks, and the rapid rise to normal power by the eighth or ninth week, as compared with hips in which the lesser trochanter is not avulsed.

Experiments were performed upon the cadaver to determine the amount of movement of the lesser trochanter. Radiographs were taken after division of the lesser trochanter and displacing it to a comparable position as seen in the living (Fig. 6). It was found that the amount of movement of the lesser trochanter was five centimetres. 


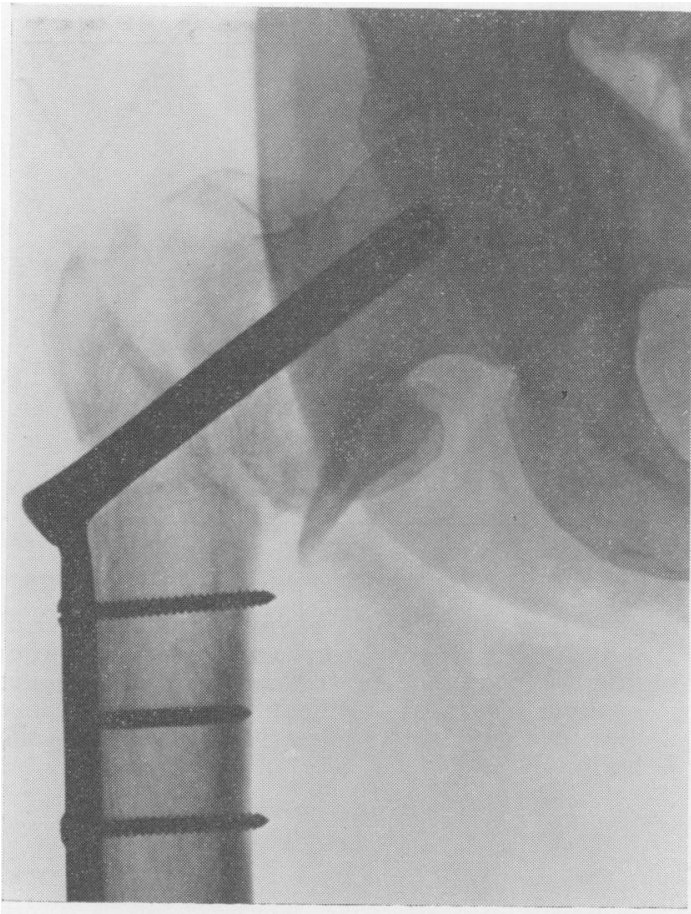

(a)

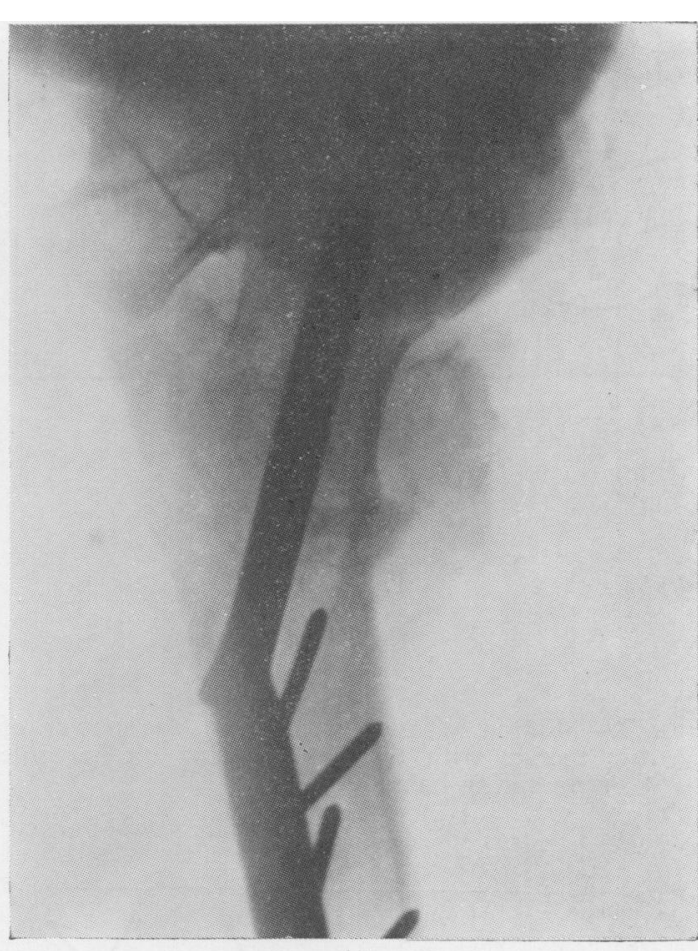

(b)

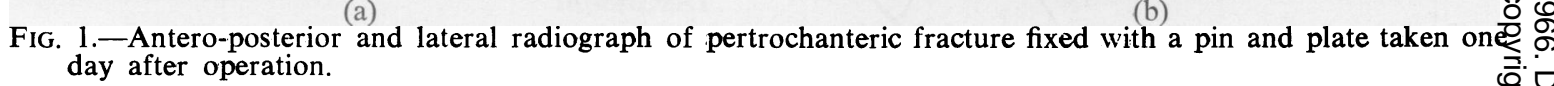

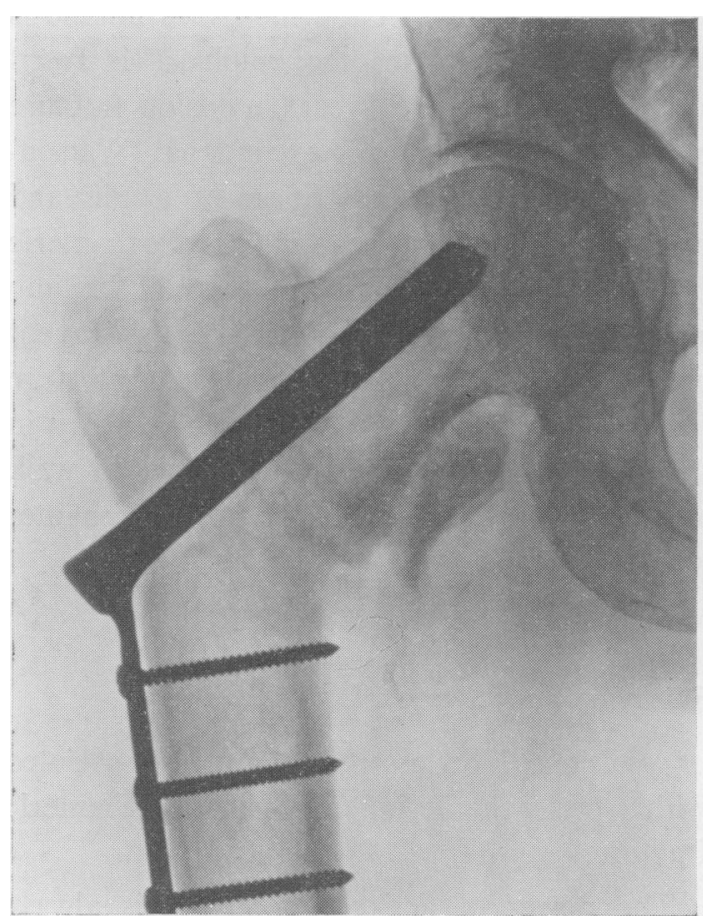

(a)

Fig. 2.-Antero-posterior and lateral radiograph taken one month after operation showing proximal movement of the lesser trochanter as compared with Fig. 1.

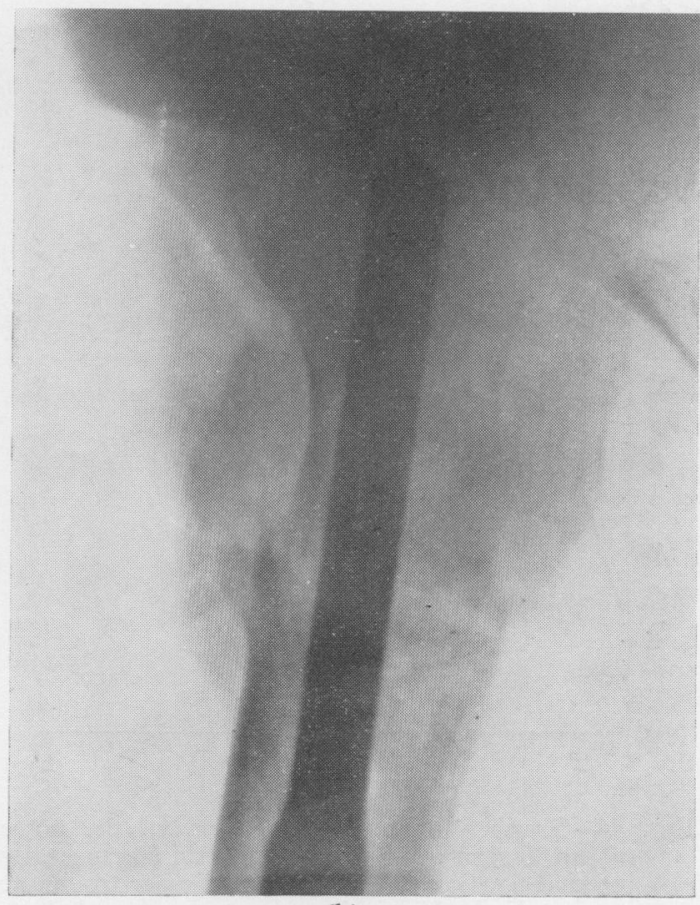

(b) 


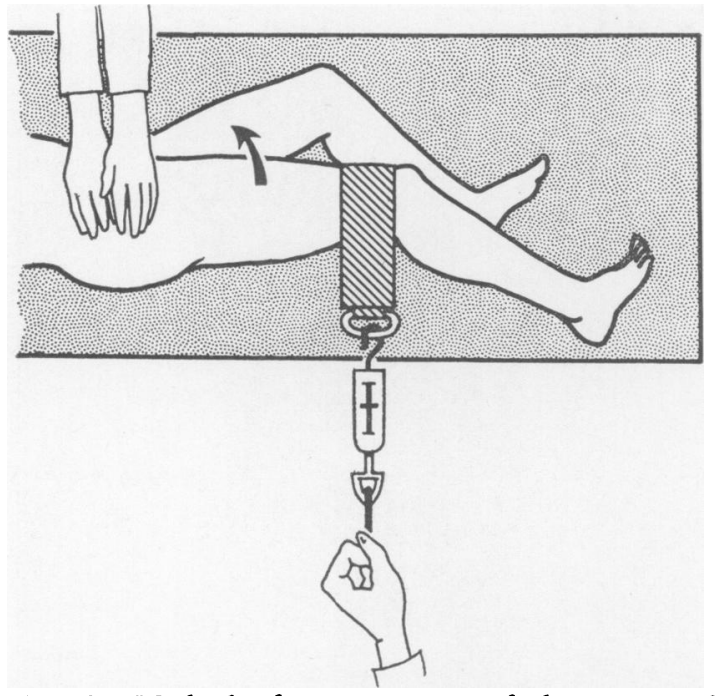

Fig. 3.-Method of measurement of the power of hip flexion with the patient lying on her side using a spring balance.

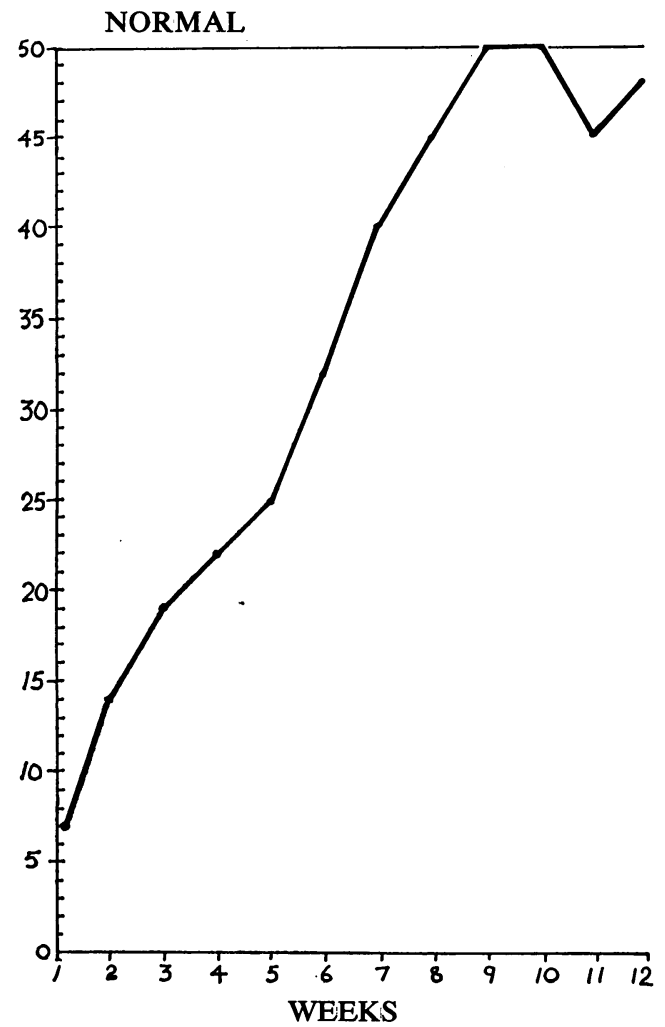

FIG. 4.-Graph showing the recovery of the power of hip flexion after pertrochanteric fracture after internal fixation of the fracture. Lesser trochanter not avulsed. Vertical ordinate spring balance measurement in pounds.

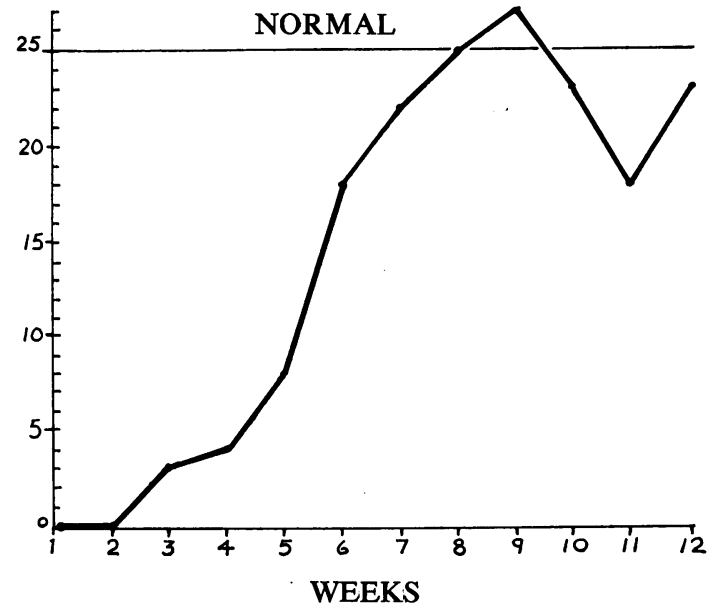

FIG. 5.-Graph showing the recovery of the power of hip flexion after pertrochanteric fracture after internal fixation of the fracture. Lesser trochanter avulsed. Vertical ordinate. Spring balance measurement in pounds. (Normal is opposite limb).

\section{Discussion}

Avulsion of the epiphysis of the lesser trochanter by the pull of the ilio-psoas muscle is? not uncommon. After the epiphysis is fused at the age of eighteen years, avulsion fracture of the lesser trochanter is exceptional (WatsonJones, 1955). The application of a pin and plate to pertrochanteric and intertrochanteric fractures has resulted in mobilisation of the limb and more activity on the part of the patient much earlier than when these fractures were treated conservatively. When there is delay in the ability to use the limb and even to walk after operation, avulsion of the lesser trochanter may be a factor.

\section{Summary}

Avulsion of the lesser trochanter is associated with pertrochanteric and intertrochanteric fractures.

The power of active hip flexion is always decreased in the first month after internal 


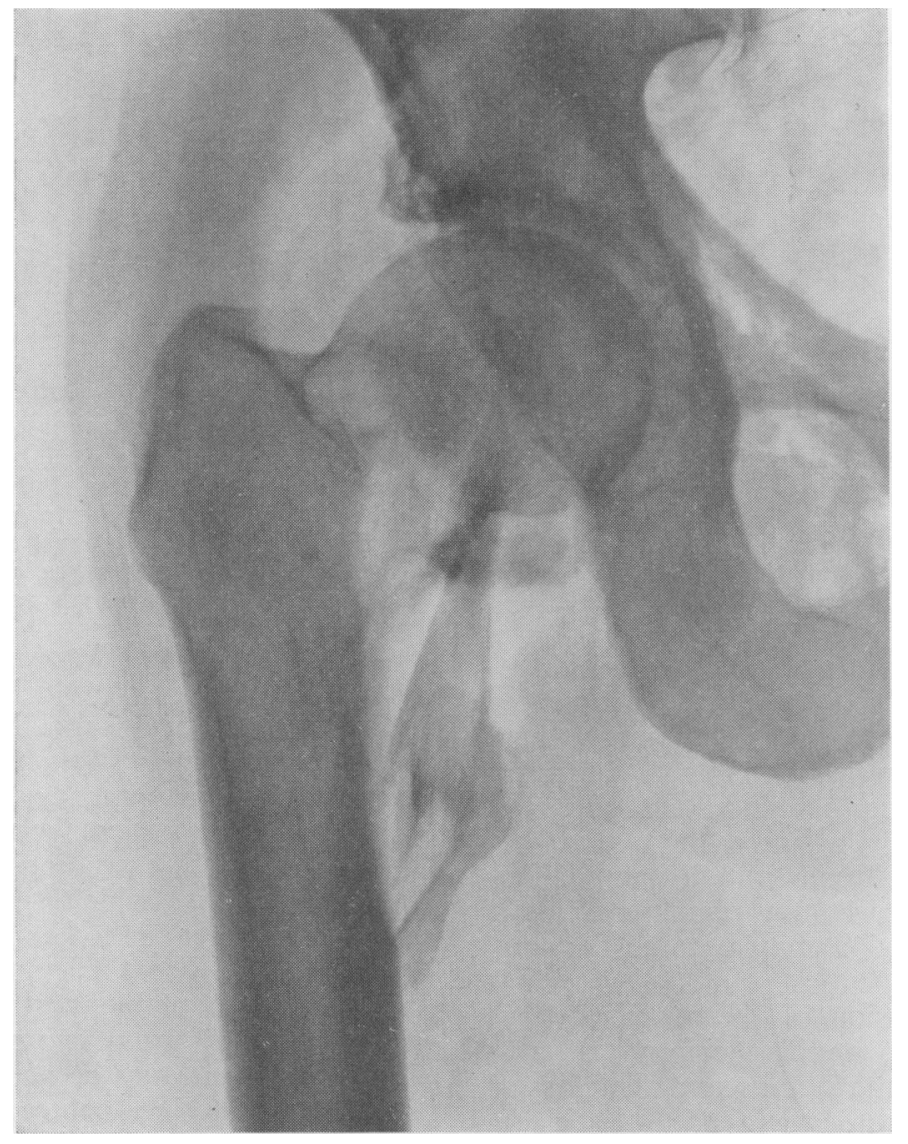

FIG. 6.-Antero-posterior radiograph after separating the lesser trochanter from the femur and displacing it proximally in the cadaver.

fixation of the fracture but recovers by the eighth week. Movement of the lesser trochanter may be as much as five centimetres.

\section{REFERENCE}

WATSON-JONES, R. (1955): Fractures and Joint Injuries. 4th ed. Vol. II, p. 653. Edinburgh and London: E. \& S. Livingstone. 